\title{
Impact of the COVID-19 pandemic on the performance of selected cardiac electrotherapy and electrophysiology procedures
}

\author{
1 Department of Electrocardiology, Medical University of Lodz, Łódź, Poland \\ 3 2nd Department of Cardiology, Medical University of Lodz, Łódź, Poland \\ 4 1st Department of Cardiology, Medical University of Lodz, Łódź, Poland \\ 5 Department of Interventional Cardiology and Electrocardiology, Medical University of Lodz, Łódź, Poland \\ 6 Department of Cardiology, Nicolaus Copernicus Hospital, Łódź, Poland \\ 7 Department of Cardio-Oncology, Medical University of Lodz, Łódź, Poland \\ 8 Department of Clinical Pharmacology, Medical University of Lodz, Łódź, Poland \\ 9 Department of Cardiology, Nicolaus Copernicus Hospital, Piotrków Trybunalski, Poland
}

Jerzy K. Wranicz¹, Jarosław Drożdż², Monika Różycka-Kosmalska1', Jarosław D. Kasprzak³, Andrzej Lubiński Grzegorz Piotrowski5,6, Marcin Kosmalski , Paweł Życiński³, Tomasz Ciurus ${ }^{8}$, Paweł Ptaszyński ${ }^{1}$, Krzysztof Kaczmarek

Correspondence to: Krzysztof Kaczmarek, MD, PhD, Department of Electrocardiology, Medical University of Lodz, ul. Pomorska 251, 92-213 tódź, Poland phone +422014360, email: krzysztof.kaczmarek@umed.lodz.pl Received: January 6, 2021 Revision accepted: March 4, 2021. Published online: March 19, 2021. Kardiol Pol. 2021; 79 (4): 452-454 doi:10.33963/KP.15884

Copyright by the Author(s), 2021
Introduction The spread of the COVID-19 pandemic has resulted in numerous changes in the daily functioning of society through interference with the economy, public, and private life. Parallelly, healthcare systems are unprecedently challenged. ${ }^{1}$ Preventive measures have been implemented to fight the pandemic and healthcare institutions focused on the treatment of infected patients. However, there have been signs of growing problems with medical care for patients with other diseases, both on an emergency and a scheduled basis. Some patients feared of presenting to the hospital or calling an ambulance and avoided timely medical assistance despite deteriorating health. ${ }^{2,3}$ To date, information concerning electrotherapy procedures in Poland was not available. Therefore, the aim of our study was to compare the number of cardiac electrotherapy and electrophysiology procedures carried out before and during COVID-19 pandemic in Łódź Province.

Methods Surveys submitted to the national consultant in cardiology were used for analysis. The surveys are carried out every year to assess healthcare related to cardiovascular diseases and include data on the number of selected electrotherapy procedures performed annually. Due to the COVID-19 pandemic, an additional mid-year survey (subdivided to the first and second quarter) was introduced in 2020. Procedures were assigned to the relevant quarter based on the date of patients' discharge from the hospital: January 1 to March 31, 2020 (first quarter) and April 1 to June 30, 2020 (second quarter). The data from 2019 were assigned in a similar way and the mean number of procedures per quarter was calculated for comparative analysis. Data on electrotherapy were collected from 13 departments providing selected procedures, both in 2019 and 2020. They included the number of implantations and replacements of pacemakers, cardiac resynchronization therapy (CRT) devices, implantable cardioverter-defibrillators (ICDs) as well as ablations of atrial fibrillation (AF) and ventricular tachyarrhythmia (VT). Transvenous lead extraction procedures were also analyzed.

As the study reanalyzed publicly available administrative data and did not involve any intervention either in the diagnostic workup or treatment of the study patients, no special bioethics committee approval was required.

Statistical analysis Statistical analysis was performed using the Statistica 12.5 software (StatSoft, Tulsa, Oklahoma, United States). Data distribution was verified for normality using the Shapiro-Wilk test and distribution other than normal was observed in all study groups. Therefore, data were expressed as median and 
TABLE 1 Cardiac implantable electronic device insertions, transvenous lead extractions, and selected ablation procedures performed in the analyzed time periods

\begin{tabular}{|c|c|c|c|c|c|c|c|}
\hline \multicolumn{2}{|c|}{ Procedure ${ }^{a}$} & $\begin{array}{l}\text { Quarterly mean } \\
\text { (2019) }\end{array}$ & $\begin{array}{l}\text { First quarter } \\
(2020)\end{array}$ & $\begin{array}{l}\text { Second quarter } \\
(2020)\end{array}$ & $P$ value $^{\mathrm{b}}$ & $P$ value & $P_{\text {value }}{ }^{d}$ \\
\hline \multirow[t]{2}{*}{ VVI } & De novo implantations $(n=11)$ & $86(16[6-29])$ & $57(4[1-5])$ & $39(2[0-3])$ & 0.81 & 0.07 & 0.16 \\
\hline & Replacements $(n=8)$ & $60(3[2-37])$ & $52(3[0-5])$ & $25(0[0-3])$ & 0.93 & 0.02 & 0.03 \\
\hline \multirow[t]{2}{*}{ AAI } & De novo implantations $(n=1)$ & 8 & 23 & 0 & - & - & - \\
\hline & Replacements $(n=1)$ & 9 & 1 & 2 & - & - & - \\
\hline \multirow[t]{2}{*}{ DDD } & De novo implantations $(n=13)$ & $\begin{array}{l}265(52[49- \\
109])\end{array}$ & $222(10[5-22])$ & $199(11(6-15])$ & 0.12 & 0.01 & 0.003 \\
\hline & Replacements $(n=13)$ & $56(5[2-25])$ & $52(1[0-10])$ & $38(1[0-4])$ & 0.55 & 0.01 & 0.37 \\
\hline \multirow[t]{2}{*}{ CRT-P } & De novo implantations $(n=8)$ & $10(0[0-5])$ & $13(0[0-2])$ & $9(0[0-0])$ & 0.61 & 0.67 & 0.36 \\
\hline & Replacements $(n=4)$ & $3(0[0-0])$ & $8(0[0-1])$ & $2(0[0-0])$ & 0.07 & 0.72 & 0.11 \\
\hline \multirow[t]{2}{*}{ CRT-D } & De novo implantations $(n=11)$ & $56(11[1-22])$ & $47(10[1-22])$ & $51(3[0-8])$ & 0.72 & 0.5 & 0.75 \\
\hline & Replacements $(n=7)$ & $15(1[0-6])$ & $13(0[0-0])$ & $12(1[0-1])$ & 0.55 & 0.4 & 0.85 \\
\hline \multirow[t]{2}{*}{ ICD } & De novo implantations $(n=12)$ & $86(27[3-36])$ & $84(6[0-10])$ & $59(6[0-10])$ & 0.67 & 0.22 & 0.2 \\
\hline & Replacements $(n=10)$ & $17(2[1-3])$ & $17(1[0-3])$ & $26(1[0-2])$ & 0.8 & 0.54 & 0.34 \\
\hline \multicolumn{2}{|c|}{ AF ablation $(n=6)$} & $134(0[0-46])$ & $99(0[0-8])$ & $81(0[0-5])$ & 0.17 & 0.047 & 0.5 \\
\hline \multicolumn{2}{|c|}{ VT ablation $(n=4)$} & $12(0[0-0])$ & $32(0[0-1])$ & $25(0[0-3])$ & 0.27 & 0.07 & 0.58 \\
\hline \multicolumn{2}{|c|}{$\operatorname{TLE}(n=3)$} & $24(0[0-0])$ & $18(0[0-0])$ & $22(0[0-0])$ & 0.11 & 0.59 & 0.18 \\
\hline
\end{tabular}

Data are presented as total number (median [interquartile range]).

a The number of centers performing the procedure is presented in parentheses.

b $P$ value for differences between the mean value in the first or second quarters of 2019 and the first quarter of 2020

c $P$ value for differences between the mean value in the first or second quarters of 2019 and the second quarter of 2020

d $P$ value for differences between the first and second quarters of 2020

Abbreviations: AAI, mode for atrial pacing; AF, atrial fibrillation; CRT-D, cardiac resynchronization therapy defibrillator; CRT-P, cardiac resynchronization therapy pacemaker; DDD, mode for dual-chamber pacing; ICD, implantable cardioverter-defibrillator; VT, ventricular tachycardia; VVI, mode for ventricular pacing; TLE, transvenous lead extraction

interquartile range (IQR). However, for better illustration, the number of procedures performed in a given quarter was also presented as a sum. The 2 study groups were compared using the Wilcoxon test, but the Bonferroni correction was applied, as multiple comparison was performed. A $P$ value less than 0.05 was regarded as significant and adjusted to a value of $P<0.017$ following the Bonferroni correction.

Results and discussion The total number of selected electrotherapy procedures in the first quarter of 2020 was similar to the quarterly mean value for 2019 (742 vs 841; median [IQR], 16 [0-42] vs 77 [0-185]; $P=0.3$ ). Conversely, the number of procedures performed in the second quarter of 2020 (590; median [IQR], 14 [0-33]) was lower than the quarterly mean value for $2019(P=0.005)$. A similar tendency was observed when the first and second quarters of 2020 were compared (TABLE1; $P=0.06$ ). These differences mainly resulted from the combined effect of fewer pacemaker implantations and replacements as well as fewer ablations due to AF (TABLE1).

In the first and second quarters of 2020, there were $13 \%$ and $37 \%$ fewer pacemakers (including
CRT pacemakers) implanted, respectively, as compared with a quarterly mean value in 2019 . Similarly, the replacements of low-energy devices decreased by $11 \%$ in the first and by $53 \%$ in the second quarter of 2020. Meanwhile, the analysis for high-energy devices (ICDs and CRT defibrillators) also showed a progressive reduction in the number of procedures, yet not as pronounced as for pacemakers and CRT pacemakers (TABLE 1). Another trend was noted for the number of VT ablations, which rose by more than 2-fold in each of the first 2 quarters of 2020 compared with quarterly means in 2019. This intriguing finding could be biased by a generally low number of ablations of this type. Nonetheless, difficult access to ambulatory and hospital care could negatively impact appropriate therapeutic management in those severely ill patients. Additionally, a higher level of stress provoked by the pandemic could have an arrhythmogenic effect. Undoubtedly, an analysis of larger datasets is needed to clarify these speculations. What is more, there was no significant reduction in the number of transvenous lead extraction procedures in the respective periods.

Our study mainly showed that the number of selected cardiac electrotherapy procedures 
decreased in the second quarter of 2020 compared with quarterly means for 2019. This difference was primarily due to the reduced number of pacemaker implantations and replacements as well as AF ablations.

Analyses carried out in several countries indicated a significant reduction in the number of hospitalizations for cardiovascular causes..$^{4,5}$ The data of one of Spanish cardiology centers from the time period before (from January 17 to March 3, 2020) and after the appearance of the first infected patients (from March 4 to April 19, 2020), showed a nearly $70 \%$ reduction in cardiovascular hospitalizations (1.46 and 4.4 hospital admissions per day, respectively). The number of admissions due to arrhythmias fell by $60 \%$, more significantly for tachyarrhythmias than for bradycardias. It also resulted in a $59.4 \%$ reduction in the number of implantations (32 vs 13) and a $81.8 \%$ decrease in electrophysiology procedures (11 vs 2$){ }^{6}$ Those data are in line with our observations. The first patient infected with the new coronavirus was diagnosed in Poland on March 4, 2020, but the total number of infected patients was relatively low in the first quarter of 2020. Consequently, the impact of the pandemic on hospitalizations due to non-COVID-19 reasons was not so evident at that time. Later, the spreading SARS-CoV-2 infection resulted in governmental restrictions including lockdown and a reduction of medical services unrelated to the pandemic could be observed.

In 10 Italian hospitals, a decrease in the number of urgent pacemaker implantations was noted during the 6 weeks following the outbreak of the pandemic compared with the situation at 6 weeks earlier (from 122 to 88 [-28\%]; $P=0.02$ ). ${ }^{7}$ A similar number of pacemaker implantations was performed during the 6 weeks to February 21, 2019 and in the corresponding time period in 2020 (119 vs 122 [+3\%]; $P=0.8$ ). After that date, the number of pacemaker implantations in 2019 remained similar $(\mathrm{n}=123)$, while in 2020 , it fell to 88 (-29\%; $P=0.02){ }^{7}$ Our data indicated a similar, approximately $30 \%$ reduction in implantations of pacemakers, especially dual-chamber devices.

German researchers compared data from 66 hospitals of the Helios network and reported a significant reduction in the number of ablation procedures between March 1, 2020 and April 30, 2020 compared with January 1 to February 28, 2020 and March 1 to April 30, 2019 (208 vs 277 vs 264, respectively; $P<0.01$ and $P=0.01),{ }^{8}$ which is in line with our observations. Interestingly, we did not record a lower incidence of VT ablations; on the contrary, the number of these procedures was higher. We cannot reliably explain this finding, as data on fluctuations regarding the number of VT ablations performed were scarce and the total number of ablations was limited (to 12 to 35 quarterly).

Similar to other authors, we hypothesize that such a decrease may have reflected patients' concerns about the safety of hospitalization. Despite all protection measures against SARS- CoV-2 recommended by medical societies ${ }^{9}$ and introduced in healthcare centers, patients were extraordinarily cautious or even afraid of medical contact, which resulted in a lower number of non-COVID-19-related patient visits. ${ }^{10}$ Our findings along with observations of other authors could be an argument for incorporating and developing telemedicine solutions in routine medical care.

Our report was mainly limited by: 1) survey methodology; 2) a relatively low number of medical centers performing particular procedures (that is, VT ablations), which affected statistical analysis; 3) shortage of some relevant medical information (among others, primary and secondary prevention in the case of ICD implantations, etiology of arrhythmias, data on other types of electrophysiological procedures), which resulted from the analysis of administrative data.

\section{ARTICLE INFORMATION}

\section{CONFLICT OF INTEREST None declared.}

OPEN ACCESS This is an Open Access article distributed under the terms of the Creative Commons Attribution-NonCommercial-NoDerivatives $4.0 \mathrm{In}$ ternational License (CC BY-NC-ND 4.0), allowing third parties to download articles and share them with others, provided the original work is properly cited, not changed in any way, distributed under the same license, and used for noncommercial purposes only. For commercial use, please contact the journal office at kardiologiapolska@ptkardio.pl.

HOW TO CITE Wranicz JK, Dróżdż J, Różycka-Kosmalska M, et al. Impact of the COVID-19 pandemic on the performance of selected cardiac electrotherapy and electrophysiology procedures. Kardiol Pol. 2021; 79: 452-454. doi:10.33963/ KP.15884

\section{REFERENCES}

1 Nicola M, Alsafi Z, Sohrabi C, et al. The socio-economic implications of the coronavirus pandemic (COVID-19): a review. Int J Surg. 2020; 78: 185-193.

2 Rosenbaum L. The untold toll - the pandemic's effects on patients without Covid-19. N Engl J Med. 2020; 382: 2368-2371.

3 Goulabchand R, Claret PG, Lattuca B. What if the worst consequences of COVID-19 concerned non-COVID patients. J Infect Public Health. 2020; 13: 1237-1239. 4 Enache B, Claessens YE, Boulay F, et al. Reduction in cardiovascular emergency admissions in Monaco during the COVID-19 pandemic. Clin Res Cardiol. 2020: 1-2. 5 Oikonomou E, Aznaouridis K, Barbetseas J, et al. Hospital attendance and admission trends for cardiac diseases during the COVID-19 outbreak and lockdown in Greece. Public Health. 2020; 187: 115-119.

6 Caamaño MN, Flores JP, Gómez CM. Impact of COVID-19 pandemic in cardiology admissions. Med Clin (Barc). 2020; 155: 179-180.

7 Migliore F, Zorzi A, Gregori $D$, et al. Urgent pacemaker implantation rates in the Veneto Region of Italy after the COVID-19 outbreak. Circ Arrhythm Electrophysiol. 2020; 13: e008722.

8 Bollmann A, Hohenstein S, Meier-Hellmann A, et al. Emergency hospital admissions and interventional treatments for heart failure and cardiac arrhythmias in Germany during the Covid-19 outbreak: insights from the German-wide Helios hospital network. Eur Heart J Qual Care Clin Outcomes. 2020; 6: 221-222.

9 Kempa M, Gułaj M, Farkowski MM, et al. Electrotherapy and electrophysiology procedures during the coronavirus disease 2019 pandemic: an opinion of the Heart Rhythm Section of the Polish Cardiac Society. Kardiol Pol. 2020; 78: 488-492.

10 Mantica G, Riccardi N, Terrone C, Gratarola A. Non-COVID-19 visits to emergency departments during the pandemic: the impact of fear. Public Health. 2020; 183: 40-41. 